\title{
Possible role of gap junction intercellular channels and connexin 43 in satellite glial cells (SGCs) for preservation of human spiral ganglion neurons
}

\section{A comparative study with clinical implications}

\author{
Wei Liu • Rudolf Glueckert • Fred H. Linthicum • Gunde Rieger • Michael Blumer • \\ Mario Bitsche • Elisabeth Pechriggl • Helge Rask-Andersen • Annelies Schrott-Fischer
}

Received: 17 June 2013 / Accepted: 19 September 2013 / Published online: 17 November 2013

(C) The Author(s) 2013. This article is published with open access at Springerlink.com

\begin{abstract}
Human spiral ganglion (SG) neurons show remarkable survival properties and maintain electric excitability for a long time after complete deafness and even separation from the organ of Corti, features essential for cochlear implantation. Here, we analyze and compare the localization and distribution of gap junction (GJ) intercellular channels and connexin 43
\end{abstract}

This study was supported by ALF grants from Uppsala University Hospital and Uppsala University and by the Foundation of "Tysta Skolan", the Swedish Deafness Foundation (HRF). Our research is part of the European Community 7th Framework Programme on Research, Technological Development and Demonstration (project acronym: NANOCI, grant agreement no. 281056). BR, Sweden kindly provided private funds.

Electronic supplementary material The online version of this article (doi:10.1007/s00441-013-1735-2) contains supplementary material, which is available to authorized users.

\footnotetext{
W. Liu $(\square)$

Department of Surgical Sciences, Section of Otolaryngology, Uppsala University Hospital, 75185 Uppsala, Sweden

e-mail:1woo24@gmail.com
}

\section{R. Glueckert $\cdot$ G. Rieger $\cdot$ A. Schrott-Fischer}

Department of Otolaryngology, Medical University of Innsbruck,

Anichstrasse 35, 6020 Innsbruck, Austria

R. Glueckert

e-mail: rudolf.glueckert@i-med.ac.at

G. Rieger

e-mail: gunde.rieger@uibk.ac.at

A. Schrott-Fischer

e-mail: annelies.schrott@i-med.ac.at

\section{F. H. Linthicum}

House Ear Institute Los Angeles, Los Angeles, CA, USA

e-mail: FLinthicum@hei.org
(Cx43) in cells surrounding SG cell bodies in man and guinea pig by using transmission electron microscopy and confocal immunohistochemistry. GJs and $\mathrm{Cx} 43$ expression has been recognized in satellite glial cells (SGCs) in non-myelinating sensory ganglia including the human SG. In man, SG neurons can survive as mono-polar or "amputated" cells with unbroken

M. Blumer $\cdot$ M. Bitsche $\cdot$ E. Pechriggl

Department of Anatomy, Histology and Embryology, Division of Clinical and Functional Anatomy, Medical University of Innsbruck, Müllerstrasse 59, 6020 Innsbruck, Austria

M. Blumer

e-mail: michael.blumer@i-med.ac.at

M. Bitsche

e-mail: Mario.Bitsche@i-med.ac.at

E. Pechriggl

e-mail: Elisabeth.pechriggl@i-med.ac.at

H. Rask-Andersen

Department of Surgical Sciences, Head and Neck Surgery,

Section of Otolaryngology, Uppsala University Hospital,

75185 Uppsala, Sweden

H. Rask-Andersen $(\bowtie)$

Departments of Otolaryngology, Uppsala University Hospital,

751 85, Uppsala, Sweden

e-mail: helge.raskandersen@gmail.com 
central projections following dendrite degeneration and consolidation of the dendrite pole. Cx43-mediated GJ signaling between SGCs is believed to play a key role in this "healing" process and could explain the unique preservation of human SG neurons and the persistence of cochlear implant function.

Keywords Spiral ganglion - Gap junction · Connexin 43 . Satellite glial cells · Cochlear implant · Human · Guinea pig

$\begin{array}{ll}\text { Abbreviations } \\ \text { CI } & \text { Cochlear implant } \\ \text { C-ret } & \text { Rearranged during transfection (receptor } \\ & \text { for GFL) } \\ \text { Cx43 } & \text { Connexin } 43 \\ \text { Cx30 } & \text { Connexin } 30 \\ \text { Cx36 } & \text { Connexin } 36 \\ \text { GDNF } & \text { Glial-cell-line-derived neurotrophic factor } \\ \text { GFL } & \text { GDNF family ligand } \\ \text { GFR alpha } & \text { GDNF family receptor alpha } \\ \text { GJ } & \text { Gap junction } \\ \text { hSGN } & \text { Human spiral ganglion neuron } \\ \text { LM } & \text { Light microscopy } \\ \text { MBP } & \text { Myelin basic protein } \\ \text { SCs } & \text { Schwann cells } \\ \text { SGN } & \text { Spiral ganglion neuron } \\ \text { SG } & \text { Spiral ganglion } \\ \text { SGCs } & \text { Satellite glial cells } \\ \text { TEM } & \text { Transmission electron microscopy } \\ \text { TUJ1 } & \text { Tubulin } \\ \text { TrkB } & \text { Tropomyosin receptor kinase B }\end{array}$

\section{Introduction}

Cochlear implants (CI) are neural prostheses used to restore hearing; they represent a remarkable success saga in medicine. Today, they bring many patients back into a world of hearing. Moreover, electric stimulation can provide a basis for prelingual deaf children to understand and develop oral speech. The results depend on the existence and maintenance of a cochlear nerve.

Despite the loss of sensory receptors and adjoining dendrites, CI function can persist, implying that human spiral ganglion neurons (SGNs) maintain electric excitability even after years of "silent inactivity". Their remarkable resistance to degeneration is verified in histological studies in which, unlike in animals, SGNs can persist as mono-polar or "amputated" cells lacking peripheral dendrites and being completely disconnected from the organ of Corti (Teufert et al. 2006).

Here, we focus on satellite glial cells (SGCs) that tightly surround neurons in sensory ganglia and human SGNs. The cells were analyzed for gap junction (GJ) intercellular channels and connexin 43 (Cx43) expression by using transmission electron microscopy (TEM) and laser confocal immunohistochemistry. Comparisons were made with another mammal (guinea pig). We speculate that Cx43-mediated GJ signaling between SGCs plays a key role in the protection and maintenance of the human auditory nerve.

\section{Materials and methods}

Studies of human materials were approved by the local ethics committee (no. 99398, 22/9 1999, cont., 2003, Dnr. 2013/190) and patient consent was obtained. Investigations of animal cochlea were approved by the local ethics committee (no. C254/4, C209/10). All studies adhered to the rules of the Helsinki declaration. Six Dunkin Hartley guinea pigs (female, 1-2 months) were used. The same procedures as those for human specimen processing were undertaken for the fixation and immunohistochemistry of the animal cochleae.

\section{TEM analysis}

The TEM analyses of human spiral ganglion (SG) and SGCs were based on ten human cochleae processed during the last 15 years (Rask-Andersen et al. 2000). The specimens were analyzed at inner ear research laboratories in both Uppsala and Innsbruck. Tissue was rinsed in cacodylate buffer (Christine Gröpl [R1104], Tulln, Austria), followed by fixation with $1 \%$ osmium tetraoxide (Christine Gröpl [R1015]) in 0.05 M cacodylate buffer at $4{ }^{\circ} \mathrm{C}$ for $4 \mathrm{~h}$. Excessive osmium tetraoxide was removed by rinsing the specimens again in cacodylate buffer. Small-sized diamond drills were used to mill off cochleae surrounding the bone. Subsequently the cochleae were decalcified in $20 \%$ ethylene-diamine-tetra-acetic acid (Titriplex III, Merck [108421], Darmstadt, Germany), pH 7.4, for 6 weeks. After decalcification, a mid-modiolar section was made and the two halves were then dehydrated in an increasing ethanol series and acetone prior to incubation in a dilution of liquid epoxy resin (Epon medium mixture: $20 \mathrm{ml}$ EMbed-812, $16 \mathrm{ml}$ dodecenyl succinic anhydride, $8 \mathrm{ml}$ nadic methyl anhydride, $1.2 \mathrm{ml}$ benzyldimethylamine; Electron Microscopy Sciences, Munich, Germany) and acetone at a ratio of $30 \%-70 \%$ for $3 \mathrm{~h}$. The specimens were infiltrated with a mixture of Epon and acetone in equal proportions at $4{ }^{\circ} \mathrm{C}$ overnight in closed vials. The next day, a mixture of $70 \%$ epoxy resin and $30 \%$ acetone replaced the liquid for $3 \mathrm{~h}$. Subsequently, tissue samples were incubated twice in $100 \%$ Epon at $4{ }^{\circ} \mathrm{C}$ for $3 \mathrm{~h}$ and overnight. Then, the pure epoxy resin was changed and the specimens were infiltrated with Epon in a vacuum chamber for $4 \mathrm{~h}$. The specimens were subsequently transferred to an embedding mold, labeled and placed in a vacuum chamber for an additional $2 \mathrm{~h}$ followed by incubation in a chamber at $60{ }^{\circ} \mathrm{C}$ for $24 \mathrm{~h}$ to increase the polymerization 
of the epoxy resin. Sections at a thickness of $1 \mu \mathrm{m}$ were cut on a Leica UC6 microtome, lightly stained with toluidine blue at $60{ }^{\circ} \mathrm{C}$ and then examined by using a light microscope.

For TEM analysis, specimens were then trimmed and ultrathin sections (90 nm thickness) were acquired and transferred to pioloform F (polyvinylacetate)-coated slot grids. Staining was performed within an automated system (Leica EM Stain) with uranyl acetate $(5 \mathrm{~g} / 1$ for $30 \mathrm{~min})$ and lead citrate $(5 \mathrm{~g} / 1$ for $50 \mathrm{~min})$ at $25^{\circ} \mathrm{C}$.

The various turns of the cochlea were analyzed and the SG from the lower basal, upper basal, lower middle, and upper middle regions was sectioned separately. Special attention was given to the structural relationship between the surrounding SGCs and Type I neurons. Sections were viewed in a JEOL 100 SX electron microscope (Uppsala) and in Zeiss LIBRA (Institute of Zoology, Innsbruck) and Philips CM 120 (Division of Anatomy, Histology and Embryology, Innsbruck) transmission electron microscopes.

\section{Control of antibody specificity against connexin 43}

We used the following controls:

Positive controls

1. Guinea pig cerebellum

2. Guinea pig heart tissue

3. Guinea pig trigeminal ganglion

4. Human cochlear tissue: (a) lateral wall, (b) organ of Corti

5. Human cochlear nerve (transitional zone)

Negative controls

1. Guinea pig spiral ganglion

2. Primary antibody omission

First, positive immunostaining characteristics were analyzed in the guinea pig lateral cochlear wall and compared with the spiral and trigeminal ganglion and cerebellum. Secondly, two different types of antibodies were used that targeted phosphorylation properties of the protein residues. These antibodies were tested on guinea pig heart muscle (Fig. 1d, e). Thirdly, negative controls were carried out by omitting the primary antibody. Finally, the staining properties of the transitional zone of the auditory nerve were studied.

\section{Cochlear fixation and sectioning of human cochlea}

The study is based on 5 human ( 2 male, 3 female; ages: $45-$ 56 years) cochleae removed during surgery. The cochleae were taken from patients with giant petro-clival meningioma, a life-threatening condition and were dissected out during a trans-cochlear operation. Most of the ears had normal pure tone thresholds before the operation. The mean pure tone thresholds (PTA) were below $15 \mathrm{~dB}$ in four patients. In one patient, values were between $25 \mathrm{~dB}$ and $35 \mathrm{~dB}$ at $2000 \mathrm{~Hz}$ and over. The cochleae were dissected out and immediately placed in $4 \%$ para-formaldehyde (PFA) in $0.1 \mathrm{M}$ phosphate-buffered saline (PBS; $\mathrm{pH} 7.4$ ). At the starting point of the fixation, the cochleae were gently perfused with fixative with a small cannula. After $24 \mathrm{~h}$ of fixation, the fixative was replaced with 0.1 M PBS and decalcification of the cochleae was carried out in 0.1 M Na-EDTA in phosphate buffer at pH 7.2. Four weeks later, the decalcified cochleae were rinsed with PBS and made ready for frozen sectioning. The cochleae were embedded in Tissue-Tek O.C.T. (Poly-sciences, Warrington, Pa., USA) and sectioned in a cryostat at $8-10 \mu \mathrm{m}$. The sections were collected on gelatin-chrome coated slides and stored below $-70{ }^{\circ} \mathrm{C}$.

Immunohistochemistry

Antibodies against Cx43, glial cell marker S-100, myelinating glial cell marker myelin basic protein (MBP) and neuron marker TUJ1 (tubulin) were employed for immunohistochemistry on the human cochlear sections in both a single- and double-staining fashion. Table 1 shows the combinations, dilutions and sources of the major antibodies used in the study. Incubation of the sections with single or mixed antibodies was carried out under the protocol as previously reported (Liu et al. 2009, 2011a, 2011b). Briefly, sections covered with antibody solution were placed in an atmosphere at $4{ }^{\circ} \mathrm{C}$ for $20 \mathrm{~h}$. Sections used as negative controls in each experiment were incubated with $2 \%$ bovine serum albumin (BSA) instead of antibodies. After incubation with primary antibodies or BSA, the sections were rinsed with PBS $(3 \times 5 \mathrm{~min})$. Sections were subjected to reaction with Alexa Fluor 488 and 555 (Molecular Probes) conjugated to secondary antibodies (Invitrogen, USA), for $2 \mathrm{~h}$ at room temperature. This was followed by counterstaining with DAPI (4',6-diamidino-2-phenylindole; Invitrogen, USA; lot no. 474302) for 5-7 min at room temperature. Sections were mounted with Vectashield (Vector Labs). As a positive Cx43 antibody control, frozen sections of guinea pig trigeminal ganglion and cerebellum were obtained by using the same methods as those used for obtaining human cochlear sections. We employed trigeminal ganglion for positive antibody control because $\mathrm{Cx} 43$ expression has been reported in the nociceptive ganglion of rodents (trigeminal ganglion, Vit et al. 2006; dorsal root ganglion, Procacci et al. 2008).

For additional immunohistochemistry of the human spiral ganglion, we used antibodies against c-Ret (rearranged during transfection, a receptor for the glialcell-line-derived neurotrophic factor [GDNF] family ligand [GFL]), i.e., monoclonal antibody from mouse RET01 (cat. no. sc-57431, Santa Cruz Biotechnology), polyclonal antibody from rabbit c-19 (cat. no. sc-167, Santa Cruz Biotechnology), polyclonal antibody from goat c-20 (cat. no sc-1290, Santa Cruz Biotechnology) 
Fig. 1 Immunohistochemistry of the human inner ear and technical controls in guinea pig cerebellum, heart and trigeminal and spiral ganglia. a Immunohistochemistry of guinea pig cerebellum. Neural marker TUJ1 (tubulin green) stains Purkinje cells and nerve processes. Expression of myelin basic protein (MBP red) is seen in the central axon but not in the peripheral nerve processes. b In the guinea pig spiral ganglion, the Schwann cells surrounding the perikarya express MBP. c Positive $\mathrm{Cx} 43$ reaction in guinea pig trigeminal ganglion cell bodies. Reaction product occurs as dots (arrow) and represents gap junction intercellular channels between individual glial cells (asterisks trigeminal ganglion neurons). Inset in c Ganglion cell bodies are TUJ1positive and surrounded by unmyelinated satellite cells that are immune-positive for S-100. d, e Immunolabeling with two different antibodies (ab1 and ab2; Table 1) against connexin 43 $(\mathrm{Cx} 43)$ in guinea pig heart muscle. f, $\mathbf{g}$ Positive immunoreaction for $\mathrm{Cx} 43$ (green) and $\mathrm{Cx} 30$ (red) in the human spiral ligament and stria vascularis. The connexin reactivity is seen both separately and co-expressed. h $\mathrm{Cx} 43$ expression in central glia in the transitional zone of the human auditory nerve. Bars $100 \mu \mathrm{m}$ $(\mathbf{a}-\mathbf{c}$, inset in $\mathbf{c}), 15 \mu \mathrm{m}(\mathbf{d}, \mathbf{e})$, $25 \mu \mathrm{m}$ (f, g), $20 \mu \mathrm{m}$ (h)
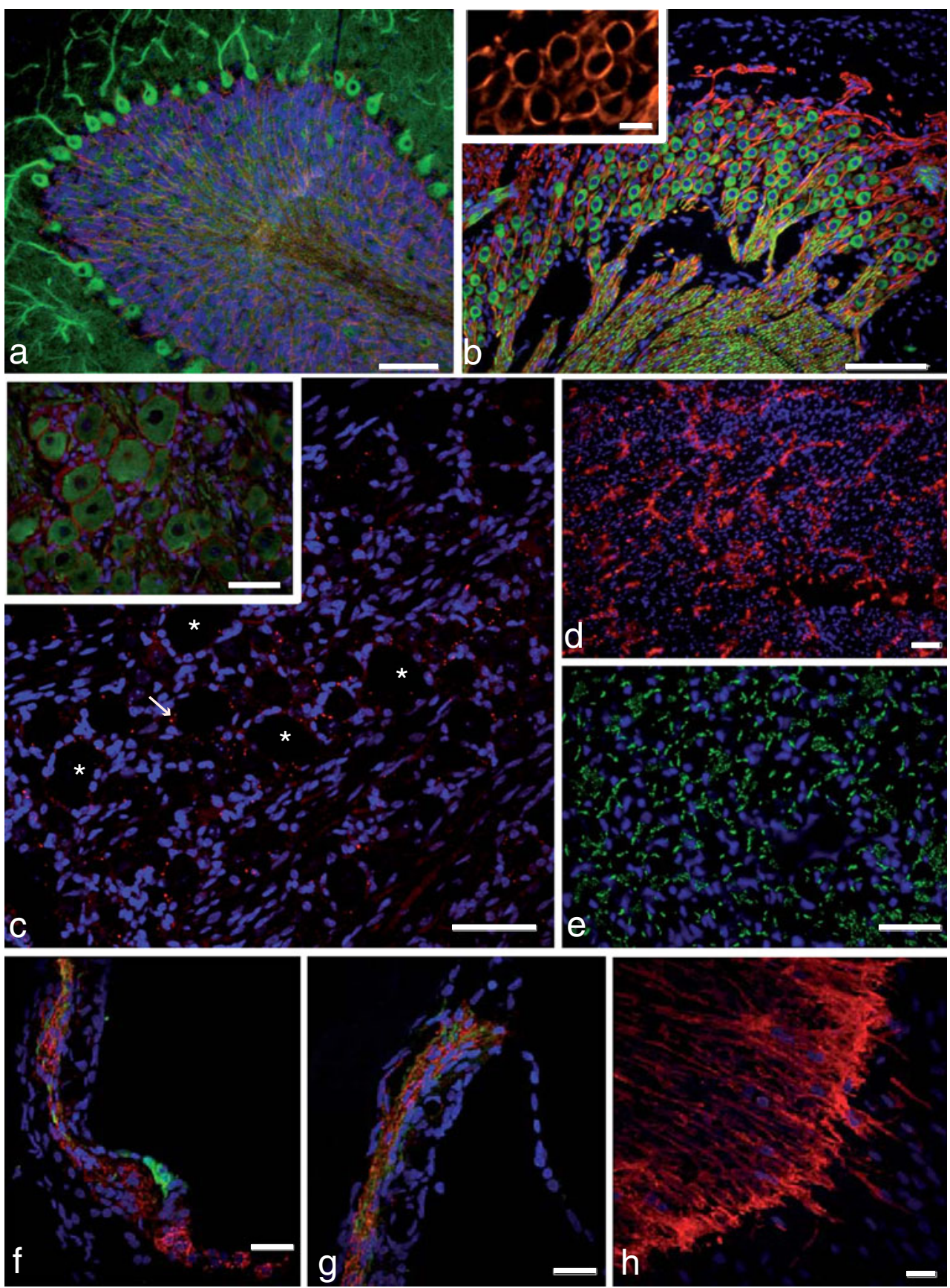

and rabbit polyclonal antibody to Ret phospho S696 (cat. no. ab4726, Abcam). The GDNF family receptor alpha 1
(GFRalpha1) antibodies that we used included a polyclonal antibody from rabbit (cat. no. AB5140, Millipore;

Table 1 Antibody characteristics and combinations (Cx43 connexin 43, MBP myelin basic protein)

\begin{tabular}{llll}
\hline Antibodies & Dilutions & Characteristics & Hosts \\
\hline Anti-Cx43 (ab1; cat. no. 13-8300, Zymed), anti-tubulin (Chemicon) & $1: 200,1: 200$ & Polyclonal, monoclonal & Rabbit, mouse \\
Anti-Cx43 (ab2; cat. no. MAB 3068, Millipore), anti-tubulin (Chemicon) & $1: 200,1: 200$ & Polyclonal, monoclonal & Mouse, rabbit \\
Anti-Cx43 (ab1; cat. no. 13-8300, Zymed), anti-MBP (Sigma) & $1: 100,1: 100$ & Polyclonal, monoclonal & Rabbit, rat \\
Anti-S100 (DAKO), anti-tubulin (Chemicon) & $1: 300,1: 200$ & Polyclonal, monoclonal & Rabbit, mouse \\
\hline
\end{tabular}


dilution 1:50) and GFRalpha1 polyclonal antibody N-18 from goat (cat. no. sc-6156; Santa Cruz Biotechnology). The GFRalpha2 antibody (H-89) was a rabbit polyclonal antibody (cat. no. sc-28953, Santa Cruz Biotechnology; dilution 1:50). Neurturin antibody was a rabbit polyclonal antibody (cat. no. ab49203, Abcam) and has no cross reactivity with GDNF. GDNF (B-8) antibody was a monoclonal antibody from mouse (cat. no. sc-13147, Santa Cruz Biotechnology; dilution 1:50). Persephin (PSPN) antibody was a mouse monoclonal antibody (cat. no. MAB2388, R\&D; dilution 1:100). Artemin (Artn) antibody was a goat polyclonal antibody (cat. no. sc-9329, Santa Cruz; dilution 1:100). This information is taken in part from Liu and Rask-Andersen (2013).
Confocal, fluorescent and bright-field imaging

Bright-field images were used to identify the inner ear structures. Fluorescent images were obtained by using an inverted fluorescent microscope (Nikon TE2000, Japan) equipped with a fluorescence unit and a digital camera with three filters (for emission spectra at 358,461 and $555 \mathrm{~nm}$ ) and connected to a computer system including image-merging software. For confocal microscopy, we used a Nikon TE2000 microscope equipped with a laser imaging system having three different filters. A computer-based program, EZ-C1, was used for storing images and reconstructing $z$-stack images into threedimensional (3-D) images. All images were saved as uncompressed JPG files.
Fig. $2 \mathrm{Cx} 43$

immunohistochemistry in trigeminal and spiral ganglion of the guinea pig. a MBP and TUJ1 expression in the trigeminal ganglion of the guinea pig. Nerve fibers are MBP-positive (red) with no MBP expression in SGCs surrounding neural cell bodies (green). b SGCs express Cx43 (arrow, green dots). Red represents TUJ1. c Guinea pig SGNs are TUJ1-positive but show no expression of $\mathrm{Cx} 43$. Inset SGN at higher magnification. Bars $100 \mu \mathrm{m}$ (a), $20 \mu \mathrm{m}(\mathbf{b}), 50 \mu \mathrm{m}(\mathbf{c})$
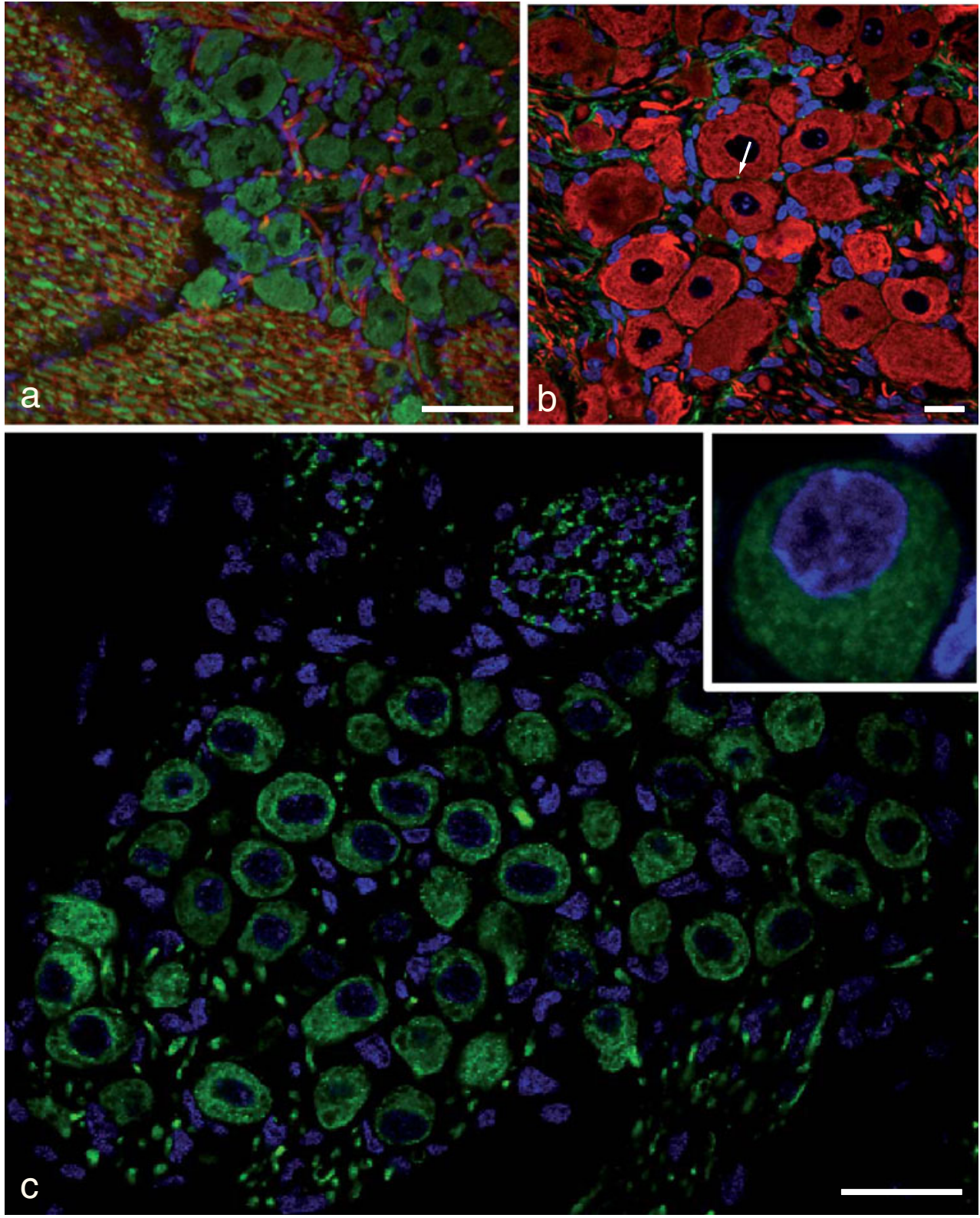


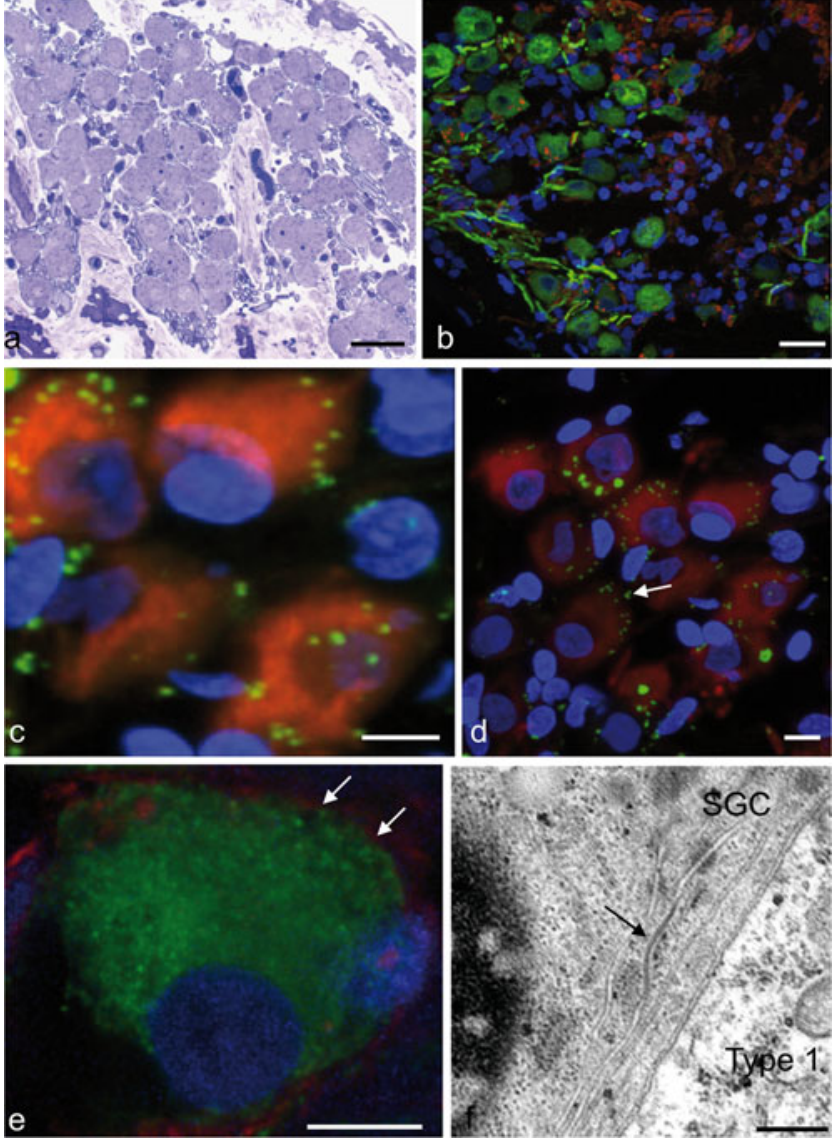

Fig. 3 Light microscopy, transmission electron microscopy (TEM) and immunofluorescence of human spiral ganglion (SG). a Semi-thin section of a normal human SG fixed in Karnovsky's fixative (petroclival meningioma, normal audiogram, osmium/toluidine staining). Spiral ganglion neuron (SGN) cell bodies are surrounded by unmyelinated SGCs. b Immunohistochemistry of a corresponding region in a formaldehydefixed specimen showing TUJ1-positive SGN cell bodies and axonal processes expressing TUJ1 (green) and MBP (red). The axonal processes (hillock) display regions with no myelin expression (approximately 50 $\mu \mathrm{m})$. c, d Cx43 expression (green dots) is seen along the peripheral border of SGN soma between surrounding satellite glial cells (arrow in d). 3-D video shows the human SG and Cx43-immunoreactive dots superimposed on neuron cell bodies (Supplementary material). e Higher magnification of a TUJ1-positive (green) human SG cell body. Cx43 labeling is in red (arrows). f TEM image of a human SG (normal hearing) showing a gap junction (arrow) between satellite glial cells $(S G C$, left) surrounding a Type 1 SGN (right). Bars $20 \mu \mathrm{m}(\mathbf{a}, \mathbf{b})$, $10 \mu \mathrm{m}(\mathbf{c}, \mathbf{d}), 5 \mu \mathrm{m}(\mathbf{e}), 0.5 \mu \mathrm{m}(\mathbf{f})$

\section{Results}

\section{Guinea pig}

Immunohistochemical expression of MBP, neural marker TUJ1, S-100 and connexin 43 were verified in guinea pig cerebellum, heart muscle and trigeminal and spiral ganglia (Fig. 1). The spiral ganglion cell bodies were TUJ1-positive and surrounding Schwann cells (SCs) expressed MBP (Fig. 1b). The trigeminal ganglion cell bodies were TUJ1-
Fig. 4 Spiral ganglion mono-polar cells in deafness and satellite cell gap junctions $(G J)$. a Celloidin section showing SG in Rosenthal's canalbasal turn in a female, aged 52 at death. She had mumps at age 2 and was deaf thereafter. The histology shows cochlear and saccular degeneration with no structures remaining in the cochlea except for the spiral ligament and 12,000 mono-polar ganglion cells (no dendrites). The vascular supply is normal. Note the physical relationship between the neural perikarya and blood vessels (arrows in inset). b Graphic illustration of two human mono-polar or "amputated" SG cells with surrounding SGCs (red) together with results from immunohistochemistry (\#TrkB tyrosine kinase $\mathrm{B}$ receptor, $B D N F$ brain-derived neurotrophic factor, $n N O S$ nitric-oxide synthase, GFL GDNF family ligand, $C$-ret* GFL receptor, GFRalpha* GDNF family receptor alpha, NTRN* neurturin, hSGNS human spiral ganglion cells, $S G C s$ satellite glial cells, GDNF glial-cellline-derived neurotrophic factor, ${ }^{* *} C x 30$ connexin $30,{ }^{*} C \times 36$ connexin 36, P75NTR $\S$ P75 neurotrophin receptor). c, d TEM of human SGN cell bodies surrounded by SGCs. GJs are seen between SGCs (arrows). Framed area in $\mathbf{c}$ is shown in higher magnification in $\mathbf{d}$. $*$ See Liu and Rask-Andersen (2013); \#Liu et al. (2011b); **Liu et al. (2009); §Liu et al. (2012); Voltage-gated ion channels have not been verified in human SG. Bars $30 \mu \mathrm{m}$ (a), $2 \mu \mathrm{m}$ (c), $200 \mathrm{~nm}$ (d)

positive and surrounded by unmyelinating satellite cells expressing S-100 (Fig. 1c, inset). These cells expressed Cx43 and the reaction product appeared as dots representing GJ channels between separate glial cells.

Two different antibodies (ab1 and ab2) targeting the phosphorylation properties of the protein residues of $\mathrm{Cx} 43$ were tested in guinea pig heart muscle (Fig. 1d, e). Both antibodies labeled connexin 43 but with a slightly different appearance. MBP and TUJ1 expression was seen in the trigeminal ganglion of the guinea pig (Fig. 2a, b). Nerve fibers were MBP-positive but no MBP expression was seen in SGCs surrounding neural perikarya (Fig. 2a). SGCs expressed Cx43 (Fig. 2b). Guinea pig spiral ganglion cells showed no expression of Cx43 (Fig. 2c).

\section{Human}

Various cell types in the spiral ganglion were identified by using specific markers including MBP, TUJ1, S-100 and Cx43 immunoreactivity. Double-immunostaining was used with a combination of cell marker antibodies. The antibody for MBP stained the myelin sheath of the nerve fibers, whereas SGCs surrounding the spiral neuron cell bodies were labeled with S-100 (not illustrated) and Cx43 antibody (Fig. 3). Immunohistochemistry showed TUJ1-positive cell bodies and axonal processes expressing TUJ1 and MBP. Axons near the cell body (axon hillock approximately $50 \mu \mathrm{m}$ long) often lacked MBP expression. Cx43 expression along the peripheral border of neuronal soma in SG appeared as small dots and represented GJ plaques between surrounding SGCs (Fig. 3c-e). Intercellular GJs, expressing $\mathrm{Cx} 43$, were found both between SGCs enveloping the same SGN body and amid different neuronal bodies. $\mathrm{Cx} 43$ expression suggested that this protein was the main component of GJ channels in SGCs. 3-D video reconstruction showed that $\mathrm{Cx} 43$ was located peripherally 


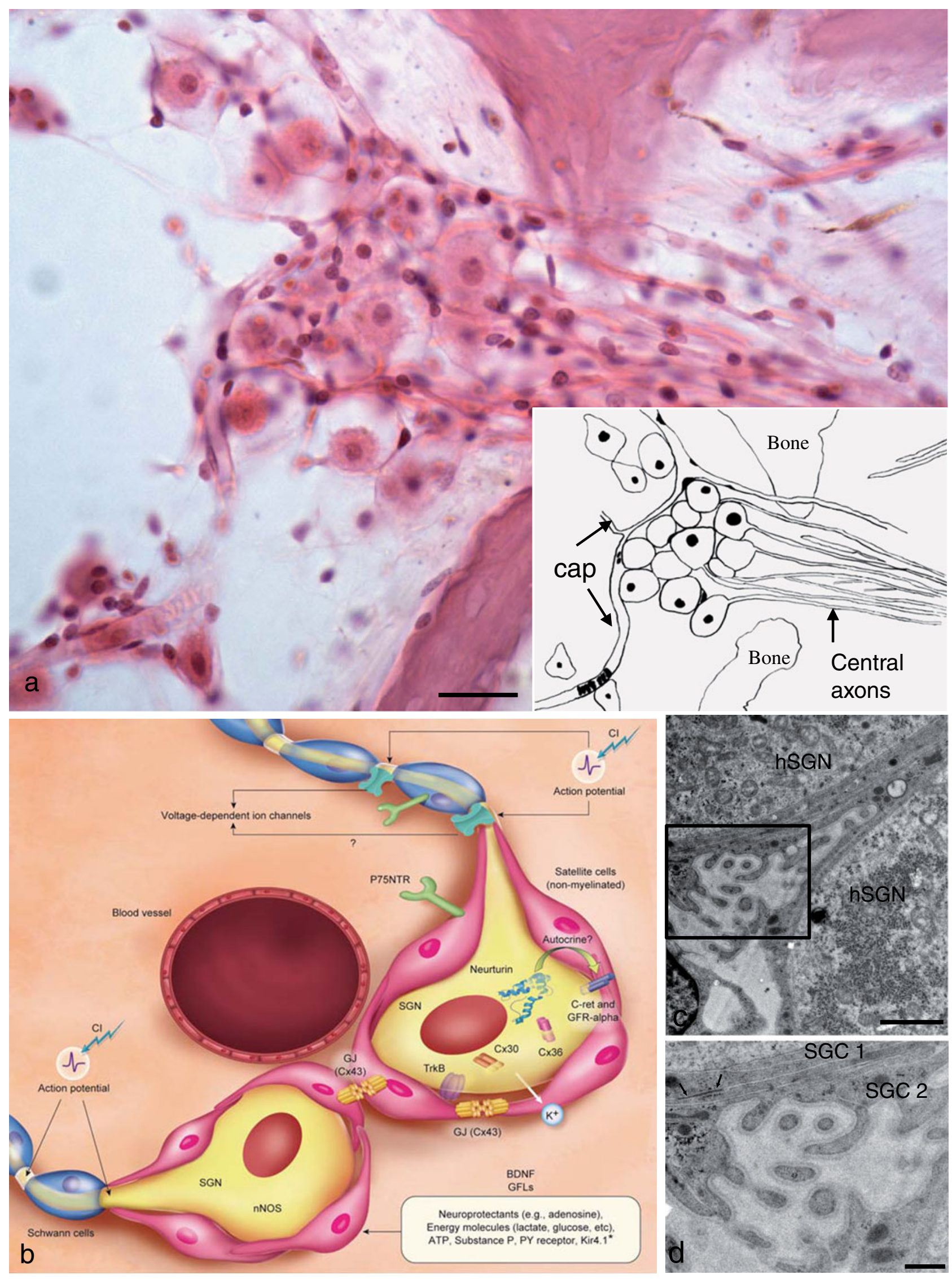


around the perikarya of the type I cell (Supplementary material).

S-100 immunostaining labeled both SGCs enveloping neuronal cell bodies and SCs lining the myelinated nerve fibers. The DAPI-stained nuclei of neurons were large, round and weakly stained, while SGCs had strongly DAPI-stained nuclei (Fig. 3c-e). Highly specific immunoreaction to $\mathrm{Cx} 43$ was seen in the human spiral ligament and stria vascularis. $\mathrm{Cx} 43$ labeling was seen both separately and co-expressed with Cx30. Typically, the epithelial cells of the spiral prominence expressed diffuse intra-cytoplasmic expression of $\mathrm{Cx} 43$ (Fig. 1f, g). Abundant $\mathrm{Cx} 43$ expression was also seen in central glia in the transitional zone of the human auditory nerve (Fig. 1h).

TEM of GJs in human spiral ganglion; comparison with guinea pig

TEM analyses showed the presence of GJs between SGCs surrounding the Type I neurons. Our findings indicated that GJs existed both between SGCs surrounding the same Type I neuron and between neighboring SGNs (Fig. 4c, d). They had a length of 4-500 nm and the intercellular distance approximated $4 \mathrm{~nm}$ between adjoining cells. At times, the SGCs were foliated and we could not establish with certainty whether the GJs were located between different SGCs or between the foliated leaflets of the same SGC.

In the guinea pig, the number of SCs that make up the sheath increases proportionately with the volume of the neuron that it surrounds. SGN in guinea pig are smaller and so fewer SCs surround an SGN. In guinea pig and cat, we mostly found only one nucleus sitting within the soma (not shown). TEM of SGNs in the guinea pig cochlea is shown in Fig. 5. The surrounding SCs form several tight myelin layers and desmosomal-like contacts can frequently be seen, whereas typical GJ-like structures are missing.

\section{Discussion}

The present study verifies our previous findings that SGCs tightly envelop the primary afferent neurons in the human SG (Liu et al. 2011a, 2011b). In addition, we have substantiated the presence of Cx43 GJ subunits in man by using TEM and immunohistochemistry. GJs might create intercellular pathways for ions and second messengers (e.g., $\mathrm{Ca}^{2+}$, inositol triphosphate, cAMP, cGMP), metabolites (e.g., glucose, amino acids, glutathione, ATP) and neuroprotectants (e.g., adenosine) to reach neighboring cells. Such couplings have been found both between SGCs surrounding individual Type I cells and between SGCs of neighboring nerve cell bodies.

$\mathrm{Cx} 43$ is the most widely expressed connexin in vertebrate tissue (Nagy et al. 2004; Yamamoto et al. 1990; Procacci et al. 2008) and is found between SGCs cells in the trigeminal ganglion (Vit et al. 2006), dorsal root ganglia (Pannese 1981; Hanani et al. 2002) and autonomic ganglia (Hanani 2010). Limited information is available about the SGCs and their reaction to damage in sensory ganglia. Animal SG architecture is highly different from that of man and confines the use of animal models to studying injury effects on auditory neurons. On being damaged, SGCs undergo structural changes and increase the expression of glial fibrillary acidic protein (Chudler et al. 1997; Stephenson and Byers 1995; Hanani et al. 2002; Vit et al. 2006). Effects of axotomy on mouse trigeminal ganglion and SGCs include increased neuronal excitability, increased ectopic firing and increased coupling between SGCs, especially between neighboring cells (Cherkas et al. 2004). These effects are believed to play major roles in the induction of neuropathic pain. Similar changes can be detected after sensory deprivation, degeneration and inflammation (Hanani et al. 2002; Pannese et al. 2003; Huang and Hanani 2005; Huang et al. 2005; Villa et al. 2010; Durham and Garret 2010; Ohara et al. 2008). SGCs and intercellular coupling are believed to regulate the ionic milieu around neurons and an alteration of $\mathrm{Cx} 43$ expression might cause changes in $\mathrm{K}^{+}$-buffering capacity resulting in lowered sensory thresholds and membrane physiological potential changes (Cherkas et al. 2004).

Additional substantiation of the neuroprotective role of $\mathrm{Cx} 43$ has been described. This connexin is a widely distributed protein in GJs in astrocytes (Giaume et al. 1991; Naus et al. 1991). In heterozygote $\mathrm{Cx} 43$ null mice and astrocyte-specific $\mathrm{Cx} 43$ null mice, increased brain damage has been observed after induced ischemia (Nakase et al. 2004). Furthermore, enhanced Cx43 immunoreactivity has been established in human brain following ischemia (Nakase et al. 2006). Another phenomenon that might highlight the role of $\mathrm{Cx} 43$ as a neural shield are the findings of preconditioning, an endogenous mechanism whereby sub-lethal hypoxic exposure increases cellular resistance. Such conditioning has not been observed in $\mathrm{Cx} 43$ null mice. In assays in vitro, such reaction has only been seen in cells expressing $\mathrm{Cx} 43$ and it deteriorates after treatment with short interfering RNA or channel blockers (Lin et al. 2008).

The distribution of connexins in the adult cochlea has previously been studied in rodents (Suzuki et al. 2003; Cohen-Salmon et al. 2002, 2004; Kikuchi et al. 1995) and also in man (Liu et al. 2009) with variable results. In recent publications, Liu et al. (2011a) have described Cx43 expression in the human cochleae as revealed by using laser confocal immunofluorescence. Cx43 is expressed as small membraneassociated dots in the SGCs. Cx43 is also expressed in the spiral limbus and spiral ligament and rabbit anti-Cx43 antibody (Invitrogen) labels the tympanic covering layer beneath the basilar membrane and the pillar and supporting cells in the organ of Corti. Because of the various phosphorylated states at the multiple different serine residues during cytoplasmic maturation and synthesis, the immune-detection of $\mathrm{Cx} 43$ gives 
various results. Differences in this pattern are explained by diverse antibodies recognizing $\mathrm{Cx} 43$ in different phosphorylated states. As a result of intracellular trafficking, connexins can stain diffusely instead as membrane plaques. In the present study with both antibodies against $\mathrm{Cx} 43$ (ab1 and ab2), we detected $\mathrm{Cx} 43$ also in the lateral wall, often co-expressed with Cx30 (Fig. 1f, g).

Corresponding Cx43-expressing channels have not been observed in guinea pig SGs. In addition, morphologic evidence of the occurrence of GJs has not been verified by TEM. GJs and $\mathrm{Cx} 43$ are expressed only in non-myelinated sensory ganglia. In man and especially in the apical region, SGCs form honeycomb-like structures enwrapping several clustered Type I neurons. Such clusters seem to increase after denervation (Fig. 4a). This suggests that cells are coupled and can act synchronously via $\mathrm{Cx} 43$, influencing nerve excitation synergistically in a larger number of primary afferents. Such coupling between SGCs, singly or between cells in clusters, might provide compensatory trophic support to neurons in case of the peripheral loss of dendrites. Physical interaction between cochlear neurons has been substantiated in a quantitative evaluation and computer-aided 3-D reconstruction of SGNs in patients with hearing loss (Felder et al. 1997) and after long-term deafness (Glueckert et al. 2005). Coupling between neighboring cells in human SG might increase resistance for further degeneration and neurons can persist as mono-polar or "amputated" cells without peripheral dendrites.

Human SGNs are generally believed to undergo retrograde degeneration as a result of peripheral sensory loss. This idea stems from results obtained from animal research in which the loss of hair cells, under experimental conditions, results in the breakdown of SGNs including their central axons (Spoendlin 1971; Webster and Webster 1981; Schuknecht 1993). In man, however, the loss of hair and supporting cells does not necessarily result in such a significant loss in SGNs (Teufert et al. 2006). Several human temporal bone studies have shown that
Fig. 5 TEM of Type I spiral ganglion neuron in guinea pig cochlea. Boxed areas in a are shown at higher magnification in b, c (SC Schwann cell, $S G N$ spiral ganglion neuron). The surrounding Schwann cell forms several tight myelin layers (a) followed by two or more (depending on the site at the neuron) loosely arranged membrane sheets (b).

Desmosomal-like contacts (arrow in c) can frequently be seen, whereas typical GJ-like structures are missing. Bars $2 \mu \mathrm{m}$ (a), $500 \mathrm{~nm}(\mathbf{b}), 500 \mathrm{~nm}(\mathbf{c})$
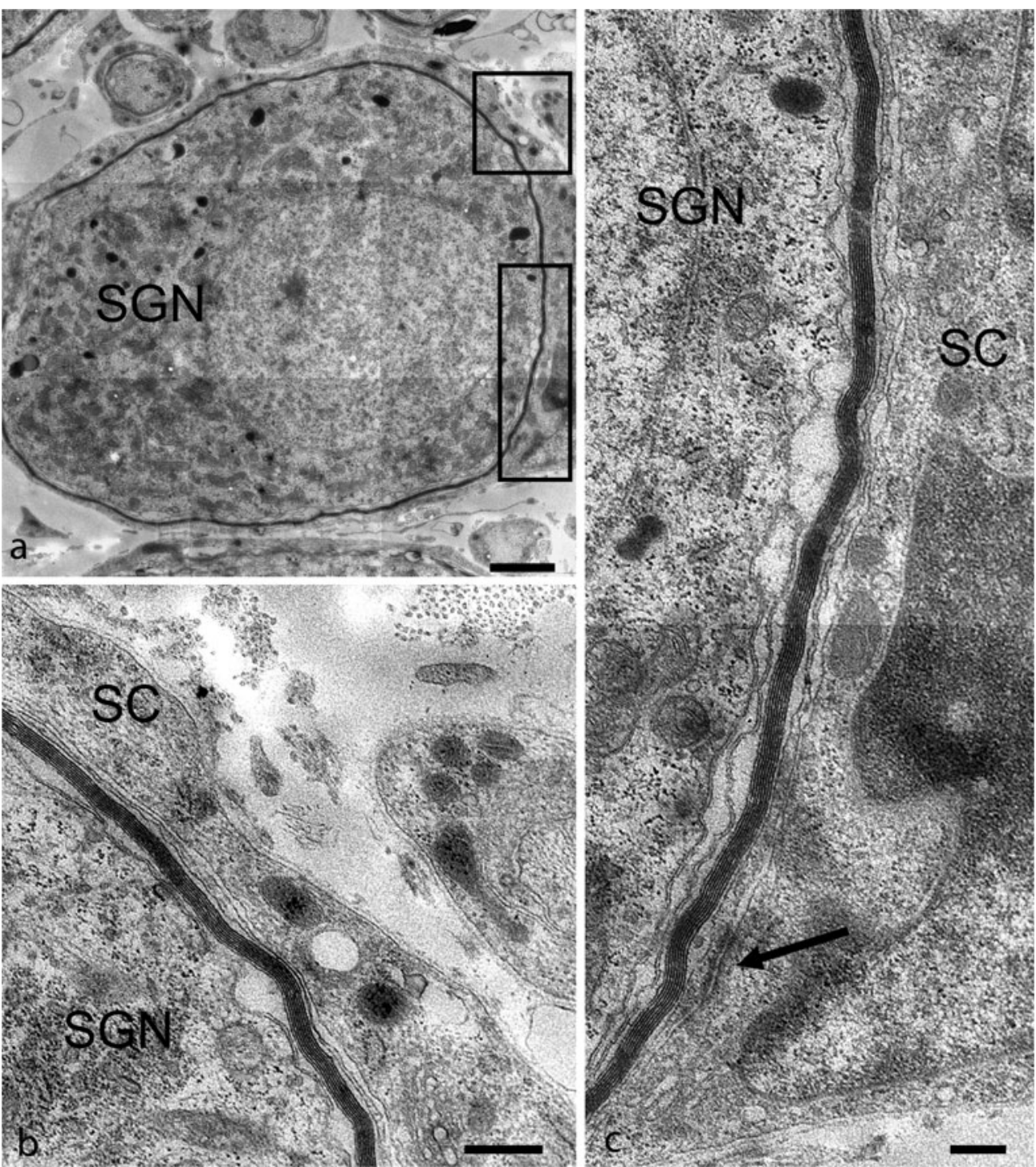
ganglion cells might well survive, despite the loss of supporting and hair cells (Kerr and Schuknecht 1968; Nadol et al. 1989; Nadol 1997; Zimmermann et al. 1995; Cureoglu et al. 2004; Kusunoki et al. 2004). Indeed, in patients with total deafness and no existing hair or supporting cells, SGNs often prevail (Linthicum and Fayad 2009). In an 89-year-old
Fig. 6 Representations of the cellular pattern of retrograde degeneration of SGNs in guinea pig and man. a Left SGNs in a normal cochlea with intact organ of Corti. Right Loss of organ of Corti with secondary loss of peripheral dendrites in an ossified cochlea. b Top In man, SGNs can survive as "mono-polar" cells with unbroken central projections following dendrite degeneration. Bottom In the guinea pig, peripheral loss of dendrites results in complete degradation of the bipolar neuron (Spoendlin 1984). A final stage of the process is reached over a period of months. A decisive factor for nerve degeneration seems to be the loss of stimulation from inner ear sensory hair cells but supporting cells might also play a role. One feasible explanation for these species differences could be the myelin/cell architecture of the SGN cell soma. In human, the dendrite pole is consolidated through a concerted action of SGCs (red cells) involving Cx43mediated GJ signaling. This prevents further degeneration. This coordination might explain the SGN perseverance and endurance of cochlear implant stimulation following long-term sensory deprivation in children and adults
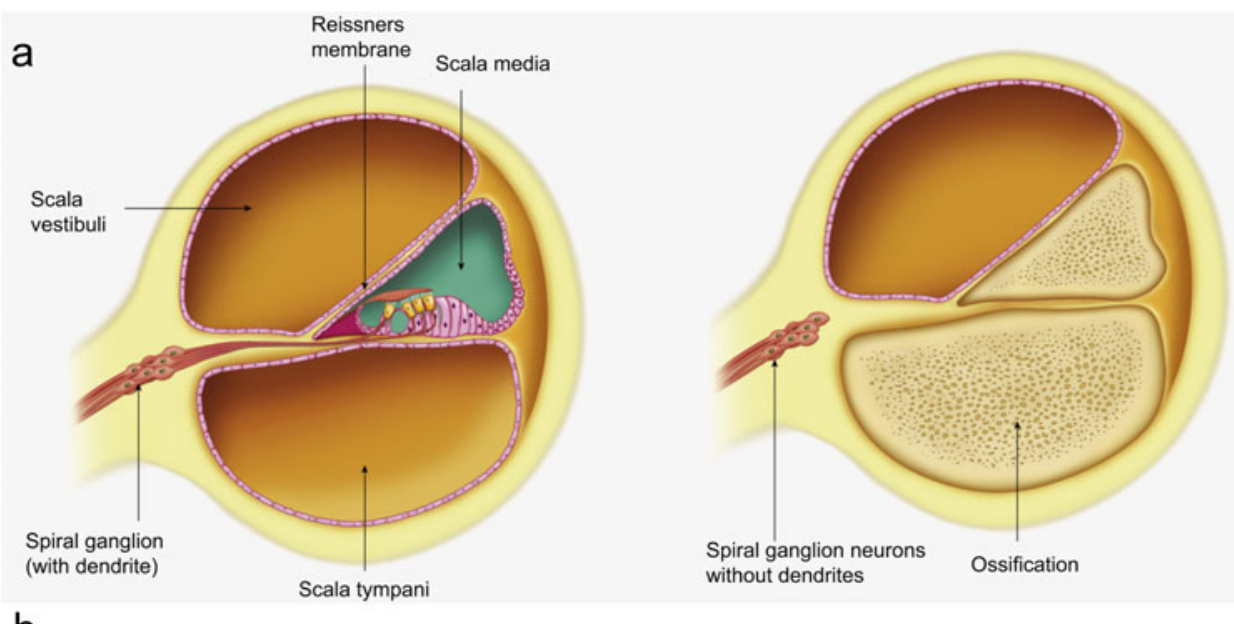

b
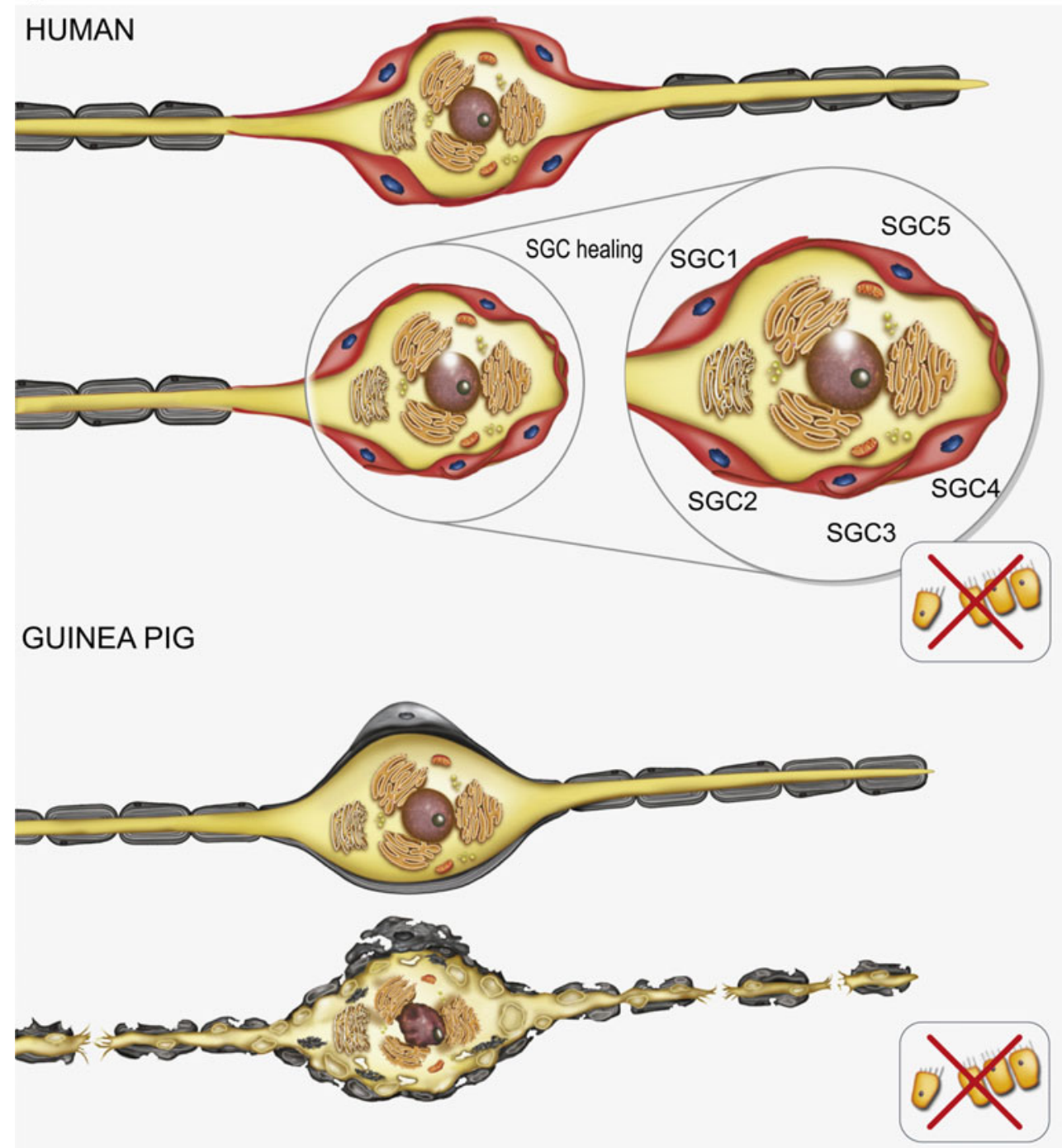
patient with total hearing loss since birth, Teufert et al. (2006) found a loss of hair cells and peripheral processes but 19,458 surviving ganglion cells. A similar case is shown in Fig. 4a.

Moreover, neural loss seems not to be significantly related to deafness duration, based on age-normative data, or to remaining supporting cell populations (Teufert et al. 2006). The number of remaining ganglion cells is not influenced by surviving peripheral processes or dendrites. SG neurons survive in Rosenthal's canal despite the fibrous obliteration of the scala tympani as long as the vascular supply is present. Instead, ganglion cell loss might be a primary concomitant loss attributable to the disease process instigated by factors causing the loss of sensory components. A similar outcome has been noted by Nadol (1997), thereby establishing that, in profoundly deaf patients, the cause of hearing loss, rather than duration, is the most important determinant of SGN cell count in man.

Since CI performance is not influenced by dendrite loss (Fayad and Linthicum 2006), we can infer that mono-polar neurons are electrically excitable and can transmit action potentials to the central nervous system even after long-term neural inactivity. Our results explain the functional durability of cochlear implants (Fig. 6).

Furthermore, as mono-polar neurons can endure in the human cochlea, an important consequence is the potential prospect for the regeneration or re-sprouting of the peripheral processes in the future. Currently, we are investigating mono-polar cells in more detail to shed further light onto these possibilities. Another significant aspect is the physiological background of tinnitus, a neuropathic pain analog. The observed changes after axotomy of the sensory nerve, such as increased SGC coupling together with increased neural excitation (Cherkas et al. 2004), could also occur in certain forms of tinnitus and thus provide new perspectives on its pathophysiology.

Open Access This article is distributed under the terms of the Creative Commons Attribution License, which permits any use, distribution and reproduction in any medium, provided the original author(s) and the source are credited.

\section{References}

Cherkas PS, Huang TY, Pannicke T, Tal M, Reichenbach A, Hanani M (2004) The effects of axotomy on neurons and satellite glial cells in mouse trigeminal ganglion. Pain 110:290-298

Chudler EH, Anderson LC, Byers MR (1997) Trigeminal ganglion neuronal activity and glial fibrillary acidic protein immunoreactivity after inferior alveolar nerve crush in the adult rat. Pain 73:141-149

Cohen-Salmon M, Ott T, Michel V, Hardelin JP, Perfettini I, Eybalin M, Wu T, Marcus DC, Wangemann P, Willecke K, Petit C (2002) Targeted ablation of connexin26 in the inner ear epithelial gap junction network causes hearing impairment and cell death. Curr Biol 12:1106-1111

Cohen-Salmon M, Maxeiner S, Krüger O, Theis M, Willecke K, Petit C (2004) Expression of the connexin43- and connexin45-encoding genes in the developing and mature mouse inner ear. Cell Tissue Res 316:15-22

Cureoglu S, Schachern PA, Paparella MM, Lindgren BR (2004) Cochlear changes in chronic otitis media. Laryngoscope 114:622-626

Durham PL, Garret FG (2010) Emerging importance of neuron-satellite glia interactions within trigeminal ganglia in craniofacial pain. Open Pain J 3:3-13

Fayad JN, Linthicum FH Jr (2006) Multichannel cochlear implants: relation of histopathology to performance. Laryngoscope 116:1310-1320

Felder E, Kanonier G, Scholtz A, Rask-Andersen H, Schrott-Fischer A (1997) Quantitative evaluation of cochlear neurons and computeraided three-dimensional reconstruction of spiral ganglion cells in humans with a peripheral loss of nerve fibres. Hear Res 105:183-190

Giaume C, Fromaget C, el Aoumari A, Cordier J, Glowinski J, Gros D (1991) Gap junctions in cultured astrocytes: single-channel currents and characterization of channel-forming protein. Neuron 6:133-143

Glueckert R, Pfaller K, Kinnefors A, Rask-Andersen H, Schrott-Fischer A (2005) The human spiral ganglion: new insights into ultrastructure, survival rate and implications for cochlear implants. Audiol Neurootol 10:258-273

Hanani M (2010) Satellite glial cells in sympathetic and parasympathetic ganglia: in search of function. Brain Res Rev 64:304-327

Hanani M, Huang TY, Cherkas PS, Ledda M, Pannese E (2002) Glial cell plasticity in sensory ganglia induced by nerve damage. Neuroscience 114:279-283

Huang TY, Hanani M (2005) Morphological and electrophysiological changes in mouse dorsal root ganglia after partial colonic obstruction. Am J Physiol Gastrointest Liver Physiol 289:670-678

Huang TY, Cherkas PS, Rosenthal DW, Hanani M (2005) Dye coupling among satellite glial cells in mammalian dorsal root ganglia. Brain Res 1036:42-49

Kerr A, Schuknecht HF (1968) The spiral ganglion in profound deafness. Acta Otolaryngol 65:586-598

Kikuchi T, Kimura RS, Paul DL, Adams JC (1995) Gap junctions in the rat cochlea: immunohistochemical and ultrastructural analysis. Anat Embryol 191:101-118

Kusunoki T, Cureoglu S, Schachern PA, Baba K, Kariya S, Paparella MM (2004) Age-related histopathologic changes in the human cochlea: a temporal bone study. Otolaryngol Head Neck Surg 131:897-903

Lin JHC, Lou N, Kang N, Takano T, Hu F, Han X, Xu Q, Lovatt D, Torres A, Willecke K, Yang J, Kang J, Nedergaard M (2008) A central role of connexin43 in hypoxic preconditioning. J Neurosci 28:681-695

Linthicum FH Jr, Fayad JN (2009) Spiral ganglion cell loss is unrelated to segmental cochlear sensory system degeneration in humans. Otol Neurotol 30:418-422

Liu W, Rask-Andersen H (2013) Immunohistological analysis of neurturin and its receptors in human cochlea. Auris Nasus Larynx (in press)

Liu W, Boström M, Kinnefors A, Rask-Andersen H (2009) Unique expression of connexins in the human cochlea. Hear Res 250:55-62

Liu W, Boström M, Kinnefors A, Edin F, Rask-Andersen H (2011a) Connexin 43 expression in the human cochlea: an immunohistochemistry study. J Hear Sci 1:21-29

Liu W, Kinnefors A, Boström M, Rask-Andersen H (2011b) Expression of TrkB and BDNF in human cochlea - an immunohistochemical study. Cell Tissue Res 345:213-221

Liu W, Glueckert R, Kinnefors A, Schrott-Fischer A, Bitsche M, RaskAndersen H (2012) P75 Distribution of P75 neurotrophin receptor in adult human cochlea-an immunohistochemical study. Cell Tissue Res 348:407-415

Nadol JB (1997) Patterns of neural degeneration in the human cochlea and auditory nerve: implications for cochlear implantation. Otolaryngol Head Neck Surg 117:220-228

Nadol JB Jr, Young YS, Glynn RJ (1989) Survival of spiral ganglion cells in profound sensorineural hearing loss: implications for cochlear implantation. Ann Otol Rhinol Laryngol 98:411-416 
Nagy JI, Dudek FE, Rash JE (2004) Update on connexins and gap junctions in neurons and glia in the mammalian nervous system. Brain Res Brain Res Rev 47:191-215

Nakase T, Söhl G, Theis M, Willecke K, Naus CCG (2004) Increased apoptosis and inflammation after focal brain ischemia in mice lacking connexin43 in astrocytes. Am J Pathol 164:2067-2075

Nakase T, Yoshida Y, Nagata K (2006) Enhanced connexin 43 immunoreactivity in penumbral areas in the human brain following ischemia. Glia 54:369-375

Naus CC, Bechberger JF, Caveney S, Wilson JX (1991) Expression of gap junction genes in astrocytes and C6 glioma cells. Neurosci Lett 126:33-36

Ohara PT, Vit JP, Bhargava A, Jasmin L (2008) Evidence for a role of connexin 43 in trigeminal pain using RNA interference in vivo. J Neurophysiol 100:3064-3073

Pannese E (1981) The satellite cells of the sensory ganglia. Adv Anat Embryol Cell Biol 65:1-111

Pannese E, Ledda M, Cherkas PS, Huang TY, Hanani M (2003) Satellite cell reactions to axon injury of sensory ganglion neurons: increase in number of gap junctions and formation of bridges connecting previously separate perineuronal sheaths. Anat Embryol (Berl) 206:337-347

Procacci P, Magnaghi V, Pannese E (2008) Perineuronal satellite cells in mouse spinal ganglia express the gap junction protein connexin 43 throughout life with decline in old age. Brain Res Bull 75:562-569

Rask-Andersen H, Tylstedt S, Kinnefors A, Illing RB (2000) Synapses on human spiral ganglion cells: a transmission electron microscopy and immunohistochemical study. Hear Res 141:1-11

Schuknecht HF (1993) Pathology of the ear, 2nd edn. Lea and Febiger, Philadelphia
Spoendlin H (1971) Degeneration behavior of the cochlear nerve. Arch Klin Exp Ohren Nasen Kehlkopfheilkd 200:275-291

Spoendlin H (1984)Factors inducing retrograde degeneration of the cochlear nerve. Ann Otol Rhinol Laryngol Suppl 112: $76-82$

Stephenson JL, Byers MR (1995) GFAP immunoreactivity in trigeminal ganglion satellite cells after tooth injury in rats. Exp Neurol 131:11-22

Suzuki T, Takamatsu T, Oyamada M (2003) Expression of gap junction protein connexin43 in the adult rat cochlea: comparison with connexin26. J Histochem Cytochem 51:903-912

Teufert KB, Linthicum FH Jr, Connell SS (2006) The effect of organ of Corti loss on ganglion cell survival in humans. Otol Neurotol 27: $1146-1151$

Villa G, Fumagalli M, Verderio C, Abbracchio MP, Ceruti S (2010) Expression and contribution of satellite glial cells purinoceptors to pain transmission in sensory ganglia: an update. Neuron Glia Biol 6: $31-42$

Vit JP, Jasmin L, Bhargava A, Ohara PT (2006) Satellite glial cells in the trigeminal ganglion as a determinant of orofacial neuropathic pain. Neuron Glia Biol 2:247-257

Webster M, Webster DB (1981) Spiral ganglion neuron loss following organ of Corti loss: a quantitative study. Brain Res 212:17-30

Yamamoto T, Ochalski A, Hertzberg EL, Nagy JI (1990) LM and EM immunolocalization of the gap junctional protein connexin 43 in rat brain. Brain Res 508:313-319

Zimmermann CE, Burgess BJ, Nadol JB (1995) Patterns of degeneration in the human cochlear nerve. Hear Res 90:192201 